\title{
The Influence of Social Presence on Acceptance of a Companion Robot by Older People
}

\author{
Marcel Heerink, Ben Kröse, Vanessa Evers and Bob Wielinga
}

\begin{abstract}
If robotic companions are to be used in the near future by aging adults, they have to be accepted by them. In the process of developing a methodology to measure, predict and explain acceptance of robotic companions, we researched the influence of social abilities, social presence and perceived enjoyment. After an experiment $(n=30)$ that included collecting usage data and a second experiment $(n=40)$ with a robot in a more and less sociable condition we were able to confirm the relevance of these concepts. Results suggest that social abilities contribute to the sense of social presence when interacting with a robotic companion and this leads, through higher enjoyment to a higher acceptance score.
\end{abstract}

Index Terms- Human robot interaction, technology acceptance, assistive technology

\section{INTRODUCTION}

T $\mathrm{N}$ THE LAST decade a growing number of research 1 projects have addressed the possibilities of robots in eldercare [1-3]. Besides in rehabilitation, where robotic technologies are already common, robots can serve as pets and fulfill roles that caregivers would fulfill. Besides to providing companionship, their functionalities can be related to supporting independent living by supporting basic activities (eating, bathing, visiting the bathroom, getting dressed) and mobility, providing household maintenance, monitoring of those who need continuous attention and maintaining safety [4-7]. Thus, robotic companions are generally considered a potentially major part of the technology that can address the problems of a growing older population and increasing labor shortage in the industrialized world.

However, there are challenges to be met - and not only technical ones. Elders do not always willingly accept new technologies and it might be crucial to map the psychological requirements that designers of robotic companions have to take into account [4]. Furthermore, robots are not only perceived as assistive devices, they are also perceived as social entities and it could be crucial for them to have certain

This work was supported in part by the Hogeschool van Amsterdam and in part by the European Commission Division FP6-IST Future and Emerging Technologies under Contract FP6-002020 (Cogniron).

Marcel Heerink is with the Instituut voor Information Engineering, Almere, Netherlands (+31-36-5480771; e-mail: m.heerink@hva.nl).

Ben Kröse is with the Institute of Informatics, University of Amsterdam, Amsterdam, the Netherlands, (e-mail: krose@science.uva.nl).

Vanessa Evers is with the Human Computer Studies Lab at the University of Amsterdam, the Netherlands (e-mail: evers@science.uva.nl).

Bob Wielinga is with the Human Computer Studies Lab at the University of Amsterdam, the Netherlands (email: wielinga@science.uva.nl) social abilities in order for communication to run smooth and naturally. It might very well be that the more natural and 'human like' the conversation with a robot is, the more enjoyment a user feels and the more this user would feel encouraged to actually use this technology. Besides, robots could have 'hedonic' aspects: users might enjoy interacting with the robot as they would enjoy playing a game or having a pleasant conversation with a person.

In our research, we address some of those challenges by exploring and modeling the factors that may influence acceptance of a conversational robot by older users [8,9]. Recent studies on human robot interaction stress the importance of social intelligent behavior in robots, even more so in a health- and eldercare environment [10-12]. This notion stems from the premise that a more socially intelligent robot will be more effective in its communication and is therefore easier and more pleasant to interact with and hence accepted easier. Inspired by these findings, we are particularly interested in the role that a robot's social abilities play in its communication with and acceptance by older users.

In order to establish the influence of (presumed) social abilities of a robot on its acceptance by older users, we developed a theoretical model and carried out two experiments that will be described in this paper. After discussing related work and introducing the theoretical framework we will describe these two experiments and present their results.

\section{RELATED WORK}

\section{A. Robots in eldercare}

Recent projects concerning eldercare companion robots focus on possible application areas and requirements for robot companions or on measuring user responses to the robots. An example of the latter is the research concerning a seal shaped robot (Paro) [6, 13, 14]. Paro's function is merely that of a social companion without any assistive functionalities, more or less comparable to a pet. These experiments showed that a robot could have the same beneficial effect on elders that a pet can have, making them feel happier and healthier. A more recently developed robot with similar pet-like functionalities is the Huggable [15].

Another example of a robot developed specifically for eldercare experiments is 'nursebot' Pearl, a robot that could actually provide advanced assistance to elders, although its functionalities were merely simulated in the reported user studies [16, 17]. 
A robot with advanced assistive functionalities to be applied in eldercare is the German Care-o-bot. It is intended to provide assistance in many ways, ranging from a walking aid to a butler $[18,19]$.

Other projects focus on an assistive environment rather then on the development of a specific robot. An example of this is the RoboCare project [20], featuring an intelligent home of which a robot is an integrated part.

The above examples of experimental robots applied in eldercare indicate the growing interest and applicability of robots in eldercare and show a research focus on dual performance where the robots are positioned as social actors as well as fulfill practical functions to support assisted living.

\section{B. Technology acceptance and robots}

Technology acceptance methodology has had much attention in the last two decades. Although there have been earlier models, an overview of technology acceptance usually starts with the introduction of the technology acceptance model (TAM) by Davis in 1986 [21, 22]. This model has become one of the most widely used theoretical models in behavioral psychology. In its most basic form it states that Perceived Usefulness and Perceived Ease of Use determine the behavioral Intention to Use a system and it poses that this behavioral intention is predicting the actual use. The model has been used for many different types of technology and has been extended with more factors that were found to influence Intention to Use or Usage.

Usually in acceptance model methodology, each factor is represented in a questionnaire by a group of questions or statements that can be replied to on a five or seven point Likert scale. The thus formed construct can often not only be related to the intention to use a system, but also directly to the Usage of a system or to each other. The validation of a model typically includes a long term observation of the actual use of technology, which makes it possible to relate scores on Intention to Use to Usage of the system.

In 2003, Venkatesh et al. [23] published an inventory of all current models and factors and presented a new model called UTAUT in which all relevant factors would be incorporated. This UTAUT model has been used by research on acceptance of a conversational robot is described by De Ruyter et al [11]. It concerned a robotic interface (the iCat made by Philips), which was tested in a Wizard of $\mathrm{Oz}$ experiment where the robot was controlled remotely by an experimenter while the participants perceived it to be autonomous. This experiment was done in a laboratory setting, with adult, but not elderly participants.

The results showed that an extravert (more expressive in voice and face) iCat was perceived to be more socially intelligent and was also more likely to be accepted by the user than a more introvert version. The same robot was used in an experiment by Looije et al. [24] where it featured as a personal assistant for a small group of people with diabetes. Results showed that participants appreciated the iCat in the high social ability condition more and that users had a higher intention of using it than was the case for a less socially intelligent iCat.

These finding show that perceived social abilities of a robot are appreciated by users as they would be in a human conversational partner. In previous research we replicated the study by de Ruyter et al. to evaluate whether the same effect exists for older users of a robotic companion [8]. In applying the UTAUT instrument, the hypothesis that social abilities contribute to the acceptance of a robot for elderly could not be confirmed. Instead, we identified new variables that seemed especially relevant to the elderly population.[8].

In the next section we will introduce the three new variables that we propose are relevant for a companion robot acceptance model for the elderly: Perceived Enjoyment, Perceived Sociability and Social Presence.

\section{MEASURING ACCEPTANCE OF ROBOTIC TECHNOLOGY BY} OLDER USERS

\section{A. Perceived Enjoyment}

The original TAM, related models and UTAUT were merely developed for and validated in a context of utilitarian systems in a working environment. Robotic technology used outside a working environment provides systems that might be experienced as more than this: users might have a sense of entertainment when using it. Van der Heijden [25] points out that in 'hedonic systems', the concept of enjoyment is a crucial determinant for the Intention to Use it.

Of course, robotic technology in eldercare will hardly be developed just to entertain: it will be partly utilitarian, partly hedonic. But even if just partly hedonic, enjoyment could prove to be a construct that needs to be part of an acceptance model for robotic technology in eldercare.

Furthermore, Perceived Enjoyment can also be of importance in utilitarian systems, as pointed out in an extensive study by Sun and Zhang [26]. The study mainly supports the claims by Venkatesh et al. [23] and Yi and Hwang [27], that Perceived Enjoyment has no direct influence on Intention to Use, but that it can influence Ease of Use and Usefulness. Still the study does also recognize that this is not a general claim for all types of systems. Indeed this could work very differently for robotic systems used by older people.

An acceptance study that also included perceived enjoyment by Chesney, concerned the use of Lego Mindstorms development environment by Mindstorms hobbyists [28]. The study, based on the viewpoint that this concerns a partly hedonic, partly utilitarian type of system, confirms perceived enjoyment having just an indirect effect on intention to use.

We may conclude that literature on acceptance models in general does attribute some influence to Perceived Enjoyment in systems that are partly or totally hedonic. Since socially interactive robots may be experienced as hedonic systems, this means Perceived Enjoyment could be of some influence. When we consider social acceptance also to be a factor, 
especially with conversational robots, this means robotic systems differ from the systems described in acceptance model literature so far and the strength of the influence of Perceived Enjoyment is still very much uncertain, especially in the context of eldercare.

\section{B. Social Presence}

Since it is not unusual for humans to treat systems and devices as social beings [29] it seems likely that humans treat embodied agents as such. The extend to which they do so seems to be related to a factor that is often related to as either 'Presence' or, more specifically 'Social presence'. Many research projects that are related to our research, incorporate this concept [30-32].

The term presence originally refers to two different phenomena. First it relates to the feeling of really being present in a virtual environment and can be defined as 'the sense of being there' [33]. Second, it can relate to the feeling of being in the company of someone: 'the perceptual illusion of non mediation' [34]. In our context, the second definition is relevant.

Regarding the close connection between social abilities and the sense of presence, there could be a crucial role for presence in the process of acceptance of functional and conversational acceptance of embodied agent technology. Therefore we intend to incorporate measuring social presence in our experiments to research its role and establish the influence of social abilities on it..

\section{Perceived Sociability}

The development social abilities for robots in general and for eldercare companions in particular is often recommended [10, 35, 36]. Nevertheless, Perceived Sociability as a construct in an acceptance model is new. We need it as such to establish weather users are conscious of the possibilities of seeing and judging a robot as a social entity. Besides, we want to measure the amount in which they perceive these abilities to see how it relates to the amount in which social presence is perceived.

In research concerning social aspects of autonomous interactive systems there are several definitions of the concept of social intelligence [37]. For the purpose of this study, social intelligence will be the social abilities, perceived by the users when interacting with robots.

A similar description is given for socially communicative robots within the classification by Breazeal [38](extended by Fong et al. [37]): robots providing a 'natural' interface by employing human-like social cues and communication modalities, that do not have to be based on deep models of social cognition.

Since we are interested in the influence of social abilities in a robotic interface on its acceptance, it is important to look at ways to measure both acceptance and social abilities. A widely used tool to evaluate social abilities for humans is Gresham \& Elliott's Social Abilities Rating System (SSRS) [39]. This tool usually is applied in social research, mostly on scholars and students, often in relationship to disabilities. Nevertheless, the five basic features (Cooperation, Empathy,
Assertion, Self-Control and Responsibility) match the aspects found in Human-Robot Interaction literature on social (or sociable) robots and agents [37], [35] well. These five constructs also appear to be relevant abilities in the study by De Ruyter et al. [11].

Other relevant concepts to study are Trust and Competence as they appear relevant in the experiments by De Ruyter et al. and research by Shinozawa et al. [40]

This leads to the following list of social abilities:

1. cooperate,

2. express empathy,

3. show assertivity,

4. exhibit self control,

5. show responsibility,

6. gain trust,

7. show competence

To translate these into programmable features, we tried to meet with the list of social behaviors, set up in the experiments by De Ruyter et al. and found the following behavioral features to be programmed into our robots character (the numbers refer to the above listed abilities) [11, 40, 41]:

- listening attentively, for example by looking at the participant and nodding $(1,2)$,

- being nice and pleasant to interact with, for example by smiling $(1,2,7)$,

- remembering little personal details about people, for example by using their names $(6,7)$,

- being expressive, for example by using facial expressions $(2,3)$,

- admitting mistakes (5, 6).

With this list we were able to incorporate all features except 'exhibit self control' (4), for which we could not find an applicable behavior in this context.

\section{Modeling the hypothesized influence of social abilities}

First of all, we want to establish the relationship between the Intention to Use the system and the actual use of it. Furthermore, we suspect Perceived Sociability (PS) to influence the sense of Social Presence (SP). This perceived Social Presence is expected to influence Perceived Enjoyment (PENJ) which can be a direct influence on the Intention to Use the system (ITU) or through Perceived Ease of Use (PEOU).

Finally, we also expect the original TAM constructs of Perceived Ease of Use an Perceived Usefulness (PU) to have a predictive influence on Intention to Use.

This leads to a model (represented graphically in Figure 1) based on the following hypotheses:

H1 Usage is predicted by Intention to Use

H2a The amount in which Social Abilities are recognized correlates with the amount in which Social Presence in perceived.

H2b The amount in which social abilities are implemented influences the amount in which Social Presence in 
perceived.

H3 Social Presence is a determining influence on Perceived Enjoyment.

H4 Perceived Enjoyment is a determining influence on Perceived Ease of Use

H5 Intention to Use is determined by Perceived Enjoyment, Perceived Ease of Use and Perceived Usefulness

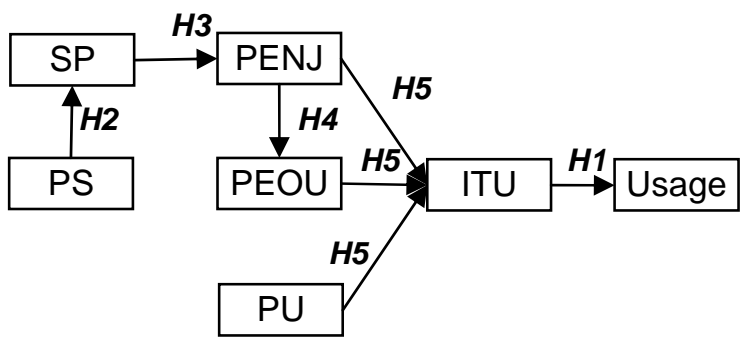

Fig. 1. Hypothetical model

\section{E. Questionnaire}

We developed a list witch three to six statements for each construct that test participants could reply to on a five point Likert scale that was transposed into verbal anchors: totally agree - agree - don't know - do not agree - totally do not agree. When processing the replies, these were related back to the 5 point scale. We wanted our participants to fill this list out themselves if possible.

Table 1 shows these statements translated into English (the original list is in Dutch).

TABLE 1

STATEMENTS FOR THE USED CONSTRUCTS

\begin{tabular}{|l|l|}
\hline Construct & Statement \\
\hline ITU & I think I'll use iCat the next few days \\
\hline ITU & I am certain to use iCat the next few days \\
\hline ITU & I'm planning to use iCat the next few days \\
\hline PU & I think iCat is useful to me \\
\hline PU & It would be convenient for me to have iCat \\
\hline PU & I think iCat can help me with many things \\
\hline PEOU & I think I will know quickly how to use iCat \\
\hline PEOU & I find iCat easy to use \\
\hline PEOU & I think I can use iCat without any help \\
\hline PEOU & $\begin{array}{l}\text { I think I can use iCat when there is someone around to help } \\
\text { me }\end{array}$ \\
\hline PEOU & I think I can use iCat when I have a good manual. \\
\hline PENJ & I enjoy iCat talking to me \\
\hline PENJ & I enjoy doing things with iCat \\
\hline PENJ & I find iCat enjoyable \\
\hline PENJ & I find iCat fascinating \\
\hline PENJ & I find iCat boring \\
\hline PS & I consider iCat a pleasant conversational partner \\
\hline PS & I find iCat pleasant to interact with \\
\hline PS & I feel iCat understands me. \\
\hline PS & I think iCat is nice \\
\hline SP & $\begin{array}{l}\text { When interacting with iCat I felt like talking to a real } \\
\text { person }\end{array}$ \\
\hline SP & It sometimes felt as if iCat was really looking at me \\
\hline SP & I can imagine iCat to be a living creature \\
\hline SP & I often think iCat is not a real person. \\
\hline SP & Sometimes iCat seems to have real feelings \\
\hline
\end{tabular}

\section{EXPERIMENTS}

To test our hypotheses we set up two experiments. The first experiment was designed to gather data of actual use of a robotic companion that could be related to the Intention to Use of this system. Besides, correlational relationships could be established between the constructs. The second experiment was designed in order to be able to compare a robot with more sociability to a less sociable one. Besides confirming the established relationship between the constructs, this could test hypothesis $\mathrm{H} 2 \mathrm{~b}$, looking at the implemented sociability (versus perceived sociability).

\section{A. Used robotic system}

The robotic agent we used in both experiment is the iCat ("interactive cat"), developed by Philips, also used in the experiments by De Ruyter et al. and Looije et al. and within our own project. The iCat is a research platform for studying social robotic user-interfaces. It is a $38 \mathrm{~cm}$ tall immobile robot with movable lips, eyes, eyelids and eyebrows to display different facial expressions to simulate emotional behavior. There is a camera installed in the iCat's nose which can be used for different computer vision capabilities.

\section{B. First Experiment}

\section{1) Experimental setup}

For our first experiment we used a setup in which the robot was connected to a touch screen as is shown in Figure 2. It could be used for information and for fun: the participants could ask for weather forecast, a television program overview or a joke by pressing the appropriate choices from a menu on the screen. The information was then given with pre-recorded speech by the iCat, for which we used a female voice. The recording was done with a text to speech engine.

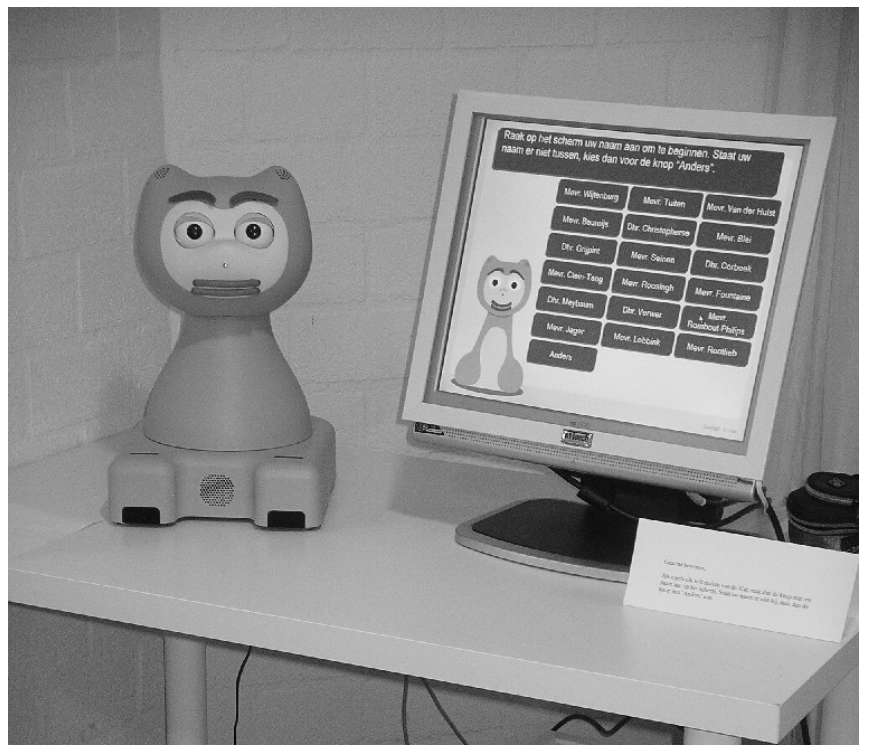

Fig. 2. Setup iCat with touch screen experiment 


\section{2) Subjects}

There were 30 participants, recruited both by eldercare personnel and by students. Their age ranged from 65 to 94 , while 22 of them were female and 8 were male. Some of them lived inside the eldercare institutions; some lived independently in apartments next to the institutions.

\section{3) Procedure}

The experiment consisted of two parts: a first initial test after which the questionnaire was used and a public use period to gather usage data.

For the initial test, participants were brought into a room were they were instructed to simply play with the robot for about three minutes. Subsequently they were brought to another room where they were given the questionnaire. They could ask for help if they were unable to read the statements.

After the initial test series were completed, we left the robot for public use in a tea room. On the screen were buttons with the names of the test session participants and one extra button saying "I'm not listed". Passers by were informed by a note that anyone could use the robot and that they could start a session by pressing the button with their name on it or the "I'm not listed" button if their name was not on the screen.

During the days the iCat was available for use to anyone passing by, the system made video recordings as soon as it was used trough the camera in its nose. Furthermore, it kept a $\log$ of the start and end times of individual user sessions. The end time was either the time a user actively ended his session or if it was not used for 90 seconds.

By comparing the video footage to the log, we could later check if users had pressed the right button.

\section{4) Results}

The test session and the questionnaire were completed by 30 participants. In analyzing the reply scores, we used Cronbach's alpha to test the reliability of the constructs. In psychology, an alpha of 0.7 and higher is considered acceptable. As table 2 shows, the constructs were highly reliable.

TABLE 2

CRONBACH'S ALPHA FOR THE USED CONSTRUCTS

\begin{tabular}{lll}
\hline \hline Construct & Items & Alpha \\
\hline Intention to use & 3 &, 961 \\
Perceived usefulness & 3 & 787 \\
Perceived ease of use & 5 &, 820 \\
Perceived enjoyment & 5 &, 836 \\
Perceived sociability & 4 &, 786 \\
Social presence & 5 &, 866
\end{tabular}

Table 3 shows the correlations between the used constructs. The correlation between usage in minutes and Intention to Use is strong, which confirms our first hypothesis. Also the other hypothesized relationships are represented by strong correlations, except for Perceived Enjoyment (PENJ) and Perceived Ease of Use (PEOU).
TABLE 3

PEARSON'S CORRELATION FOR THE USED CONSTRUCTS AND USAGE MEASURED IN MINUTES

\begin{tabular}{llllllll}
\hline & & \multicolumn{7}{c}{ ITU } & PU & PEOU & PENJ & SP & PS \\
\hline ITU & Correlation & 1 &, $504^{* *}$ &, $633^{* *}$ &, $420^{*}$ &, $599^{* *}$ &, 159 \\
& Sig (2-tailed) & &, 005 &, 000 &, 021 &, 000 &, 402 \\
PU & Correlation &, $504^{* *}$ & 1 &, $468^{* *}$ &, $551^{* *}$ &, $450^{*}$ &, 336 \\
& Sig (2-tailed) &, 005 & &, 009 &, 002 &, 013 &, 069 \\
\multirow{2}{*}{ PEOU } & Correlation &, $633^{* *}$ &, $468^{* *}$ & 1 &, 252 &, $607^{* *}$ &, 149 \\
& Sig (2-tailed) &, 000 &, 009 & &, 179 &, 000 &, 433 \\
\multirow{2}{*}{ PENJ } & Correlation &, $420^{*}$ &, $551^{* *}$ &, 252 & 1 &, $606^{* *}$ &, $583^{* *}$ \\
& Sig (2-tailed) &, 021 &, 002 &, 179 & &, 000 &, 001 \\
\multirow{2}{*}{ SP } & Correlation &, $599^{* *}$ &, $450^{*}$ &, $607^{* *}$ &, $606^{* *}$ & 1 &, $540^{* *}$ \\
& Sig (2-tailed) &, 000 &, 013 &, 000 &, 000 & &, 002 \\
PS & Correlation &, 159 &, 336 &, 149 &, $583^{* *}$ &, $540^{* *}$ & 1 \\
& Sig (2-tailed) &, 402 &, 069 &, 433 &, 001 &, 002 & \\
\multirow{2}{*}{ Min. } & Corr &, $625^{* *}$ &, 360 &, $657^{* *}$ &, $363^{*}$ &, $646^{* *}$ &, 209 \\
& Sig (2-tailed) &, 000 &, 051 &, 000 &, 049 &, 000 &, 267
\end{tabular}

\section{Second experiment}

1) Experimental setup

In our second experiment, participants were interacting with iCat through speech. Conversational scripts were developed for the iCat in two conditions: more socially communicative and less socially communicative. The more socially communicative condition exhibited the following social abilities:

- it listened more attentively (by looking at the participant and nodding while the participant was speaking);

- it smiled during the interaction,

- it remembered and used the name of the participant during the interaction;

- it was showing more facial expressions;

- it had a more expressive voice (with variable pitch);

- it would apologize for making a mistake.

The scripted dialogues for the two conditions were identical except for the participant's name being used by the more social version. All dialogues were set up with the same text to speech (tts) application.

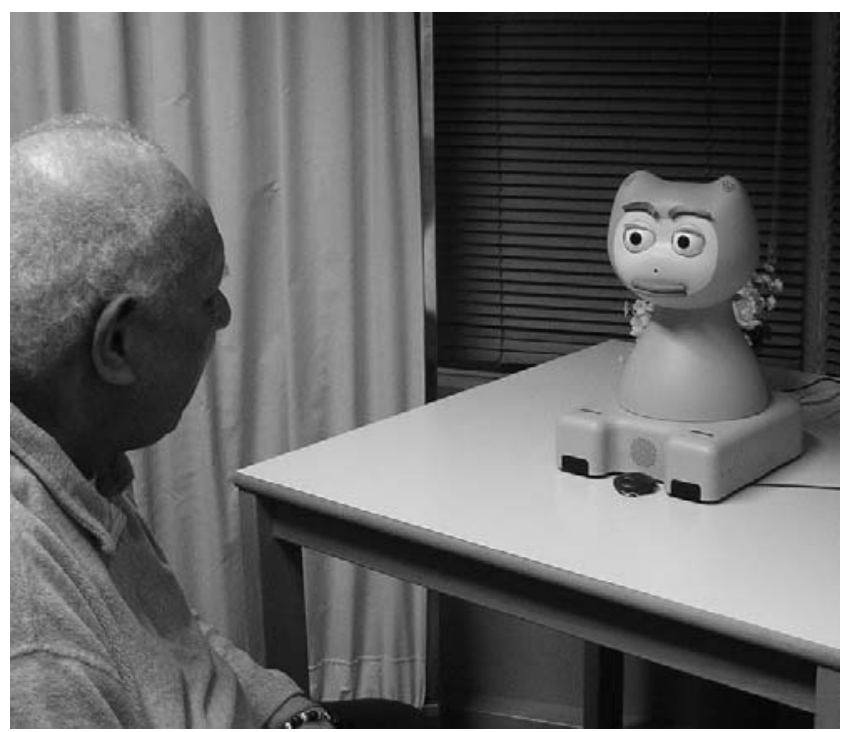

Fig. 3. Setup iCat Wizard of Oz experiment 
A specific interaction context was created where the iCat could be used in a Wizard of $\mathrm{Oz}$ fashion, which guaranteed a similar pattern for all sessions. The participants were first exposed to the iCat in groups (8 participants per group). After a short introduction by one of the researchers the robot told them what its possibilities were: an interface to domestic applications, monitoring, companionship, information providing, agenda-keeping and memorizing medication times and dates. They were told that for today's experiment, the robot was only programmed to perform three tasks: setting an alarm, give directions to the nearest supermarket and giving the weather forecast for tomorrow. The experimenter subsequently demonstrated how to have a conversation with the robot in which it performed these tasks.

After this group session, the participants were invited one by one to have a conversation with the robot, while the other group members were waiting in a different section of the room. The conversation was standardized as much as possible and we asked the participants to have the robot perform the three simple tasks. While being engaged in conversation, the participants' behavior was observed by a researcher and recorded by camera. The group session and the individual session were both about 5 minutes, so the maximum time spent with the robot was 10 minutes for each participant.

\section{2) Subjects}

Our experiment featured 40 participants between 65 and 89 years old, divided into 4 groups of 8 and 2 groups of 4 . Exactly half of the participants (2 groups of 8,1 group of 4 ) were exposed to the more sociable version and the other half to the less sociable one.

\section{3) Procedure}

A specific interaction context was created where the iCat could be used in a Wizard of $\mathrm{Oz}$ fashion, which guaranteed a similar pattern for all sessions. The participants were first exposed to the iCat in groups (8 participants per group). After a short introduction by one of the researchers the robot told them what its possibilities were: an interface to domestic applications, monitoring, companionship, information providing, agenda-keeping and memorizing medication times and dates. They were told that for today's experiment, the robot was only programmed to perform three tasks: setting an alarm, tell a joke and giving the weather forecast for tomorrow. The experimenter subsequently demonstrated how to have a conversation with the robot in which it performed these tasks.

After this group session, the participants were invited one by one to have a conversation with the robot, while the other group members were waiting in a different section of the room. The conversation was standardized as much as possible and we asked the participants to have the robot perform the three simple tasks. While being engaged in conversation, the participants' behavior was observed by a researcher and recorded by camera. The group session and the individual session were both about 5 minutes, so the maximum time spent with the robot was 10 minutes for each participant.

\section{4) Results}

In the second experiment the test session and the questionnaire were completed by 40 participants -20 for each condition. In this experiment the constructs also appear to be strong, as is shown in Table 4.

TABLE 4

CRONBACH'S ALPHA FOR THE USED CONSTRUCTS IN THE SECOND EXPERIMENT

\begin{tabular}{lll}
\hline \hline Construct & Items & Alpha \\
\hline Intention to use & 3 &, 901 \\
Perceived usefulness & 3 &, 865 \\
Perceived ease of use & 5 &, 765 \\
Perceived enjoyment & 5 &, 846 \\
Perceived sociability & 4 &, 885 \\
Social presence & 5 &, 831
\end{tabular}

Table 5 shows the t-test scores on the used constructs for the two conditions. There is a significant difference in acceptance score in favor of the more social condition.

TABLE 5

T-TEST RESULTS FOR THE TWO CONDITIONS

\begin{tabular}{lll}
\hline \hline Construct & t & Sig (2-tailed) \\
\hline Intention to use & $-2,264$ &, $029^{*}$ \\
Perceived usefulness &,- 470 &, 641 \\
Perceived ease of use &,- 928 &, 360 \\
Perceived enjoyment & $-2,043$ &, $048^{*}$ \\
Perceived sociability & $-2,208$ &, $033^{*}$ \\
Social presence & $-2,271$ &, $029^{*}$
\end{tabular}

. Also the scores for Social Presence, Perceived Enjoyment and Perceived Sociability show a significant difference

\section{Combined results}

In our two experiments, the three conditions (iCat with touch screen, more social iCat, less social iCat) concerned the same type of users with the same type of functionalities, the same robot and the same questionnaire. In order to test the relationships in our hypothetical model we combined the data of the two studies to perform a linear regression analysis on the hypothesized relationships, thus examining the probability of one construct (listed under 'Independent variables') determining the other (listed under ('Dependent variable').

The results are shown in table 4 .

TABLE 4

LINEAR REGRESSION SCORES FOR THE HYPOTHESIZED RELATIONSHIPS

\begin{tabular}{|l|l|l|l|l|l|}
\hline Hypothesis & $\begin{array}{l}\text { Independent } \\
\text { variables }\end{array}$ & $\begin{array}{l}\text { Dependent } \\
\text { variable }\end{array}$ & Beta & $\mathrm{t}$ & Sig. \\
\hline H1 & ITU & Minutes &, 625 & 4,236 &, $000^{* *}$ \\
H2 & PS & SP &, 540 & 3,399 &, $002^{* *}$ \\
H3 & SP & PENJ &, 606 & 4,033 &, $000^{* *}$ \\
H4 & PENJ & PEOU &, 163 & 1,366 &, 176 \\
\hline \multirow{3}{*}{ H5 } & PENJ & &, 382 & 3,913 &, $000^{* *}$ \\
& PEOU & ITU &, 347 & 3,329 &, $001^{* *}$ \\
& PU & &, 163 & 1,537 &, 129 \\
\hline
\end{tabular}

For H1 only the results from the first experiment $(n=30)$ were used, for the other hypotheses the results of both experiments were added $(n=70)$ 
The results confirm our first three hypotheses. The fourth hypotheses has to be rejected according to these results - a conclusion that could already be drawn from correlation analysis of our first experiment: Perceived Enjoyment does not have a predictive influence on Perceived Ease of Use. The fifth hypothesis can only partly be confirmed: Perceived Ease of Use and Perceived Enjoyment both have a predictive influence on Intention to Use. The influence of Perceived Usefulness on Intention to Use does not show despite its correlation in the first experiment. An explanation would be that the effect is captured by the determining influence of Perceived Enjoyment and Perceived Ease of Use.

\section{DISCUSSION AND CONCLUSION}

Our results show that a robot with more social abilities has a higher score on Social Presence and this results in a higher score on Perceived Enjoyment which again leads to a higher Intention to Use the system. Our first experiment showed that this Intention to Use predicts the actual use of the system.

Summarizing our findings:

H1 Prediction of Usage by Intention to Use for this type of technology and user group has been confirmed both by correlation and regression analysis on data of our first experiment.

H2a The data from our first experiment show a strong correlation between Perceived Sociability and Social Presence. Besides, regression analysis shows Perceived Sociability to be a determining influence on Social Presence.

H2b Responses to the robot in the more sociable condition in our second experiment clearly show a higher score on Social Presence.

H3 Regression analysis shows Social Presence is a determining influence on Perceived Enjoyment.

H4 We could not confirm Perceived Enjoyment to be a determining influence on Perceived Ease of Use.

H5 Intention to Use is indeed determined by Perceived Enjoyment and Perceived Ease of Use, but the influence of Perceived Usefulness does not show in a regression analysis due to the effect being captured by the other constructs.

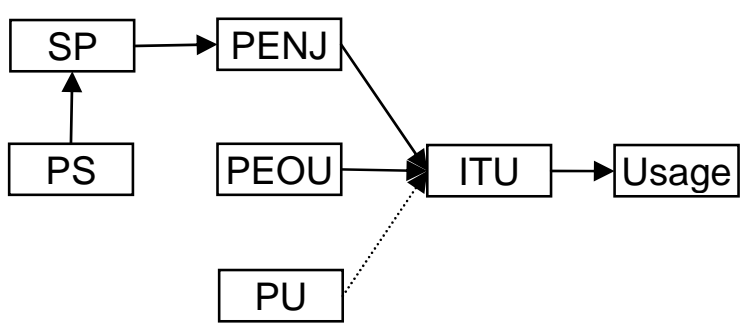

Fig. 4. Confirmed relationships

We may conclude that the sense of presence that people feel with a robot can be manipulated by changing its social abilities. This sense of presence has a positive impact on the enjoyment that is felt and this is influencing its acceptance.
Of course our experiments have been carried out with a specific non mobile robot and we have to be careful to generalize. Besides, usage data in our first experiment have been collected over a five day period: it would be interesting to see how usage patterns develop over weeks and months. Nevertheless, the significance of the data gives us some quantitative evidence that social abilities are very relevant in this context and that the 'social presence experience' is something beyond age. This means that it may be important to optimize this experience to make robots more acceptable to this specific user group.

It would be interesting to see if these conclusions are specific for this type of robot and for older users or can be generalized. Future research could focus on different robots (and perhaps screen agents) but also on different user groups and examine how the variable of user age relates to the impact of social presence. A problem that such research would face and that we also face with our present research - is the relationship between generations and experience with advanced technology. As we found in earlier research, there is a strong relationship between experience with technology such as computers and the way new technologies are experienced and evaluated. This experience is different for every generation and findings based on research on the presently older population could very well differ from what we would find in the older population of the future.

Besides, the different ways this experience can be optimized can of course be object of study, especially for this user group.

\section{ACKNOWLEDGMENT}

We like to express our gratitude to the staff and caretakers as well as the test participants of "De Kiekendief", "De Overloop" in Almere, "De Uiterton" in Lelystad and "De Emtinckhof" in Loosdrecht for their cooperation. Also we like to thank Willem Notten, Bas Terwijn and Rogier Voors for their work on programming the system and Rick van Midde, Albert van Breemen and Martin Saerbeck for their support.

\section{REFERENCES}

[1] M. Pollack, "Intelligent Technology for an Aging Population: The Use of AI to Assist Elders with Cognitive Impairment," AI Magazine, Summer, pp 9-24, 2005.

[2] R. Reddy, "Robotics and Intelligent Systems in Support of Society," IEEE Intelligent Systems, vol. 21, pp. 24-31, 2006.

[3] J. Forlizzi, "Robotic products to assist the aging population," Interactions, Volume 12 Issue 2, vol. march, pp. 16-18, 2005.

[4] J. Forlizzi, DiSalvo, C. and Gemperle, F., "Assistive Robotics and an Ecology of Elders Living Independently in Their Homes," Journal of HCI Special Issue on Human-Robot Interaction, January, pp. 25-59, 2004.

[5] E. D. Mynatt, I. Essa, and W. Rogers, "Increasing the opportunities for aging in place," Proceedings of the CUU 2000 Conference on Universal Usability, New York, 2000.

[6] W. Taggart, S. Turkle, and C. Kidd, "An interactive robot in a nursing home: Preliminary remarks," in Towards Social Mechanisms of Android Science, vol. July. Stresa, Italy: Cognitive Science Society, pp. 56-61, 2005. 
[7] L. M. Camarinha-Matos and H. Afsarmanesh, "Design of a virtual community infrastructure for elderly care," presented at 3rd IFIP Working Conference on Infrastructures for Virtual Enterprises, 2002.

[8] M. Heerink, B. J. A. Kröse, B. J. Wielinga, and V. Evers, "Studying the acceptance of a robotic agent by elderly users," International Journal of Assistive Robotics and Mechatronics, vol. 7, pp. 33-43, 2006.

[9] M. Heerink, B. J. A. Kröse, B. J. Wielinga, and V. Evers, "Enjoyment, Intention to Use and Actual Use of a Conversational Robot by Elderly People," Proceedings of The third ACM/IEEE International Conference on Human-Robot Interaction, Amsterdam, March 2008.

[10] C. Breazeal, "Socially intelligent robots," interactions, vol. 12 (March), 2005.

[11] B. de Ruyter, P. Saini, P. Markopoulos, and A. J. N. van Breemen, "Assessing the Effects of Building Social Intelligence in a Robotic Interface for the Home," Special Issue of IwC: social impact of emerging technologies, 2005.

[12] B. R. Duffy, "Anthropomorphism and The Social Robot," Special Issue on Socially Interactive Robots, Robotics and Autonomous Systems, Robotics and Autonomous Systems, vol. 42, pp. 170-190, 2003.

[13] T. Shibata, K. Wada, and K. Tanie, "Statistical Analysis and Comparison of Questionnaire Results of Subjective Evaluations of Seal Robot in Japan and U.K," presented at Proceedings of the 2003 IEEE International Conference on Robotics \& Automation, 2003.

[14] K. Wada and T. Shibata, "Robot Therapy in a Care House - Results of Case Studies," presented at Proceedings RO-MAN, 2006.

[15] W. D. Stiehl, J. Lieberman, C. Breazeal, L. Basel, R. Cooper, H. Knight, L. Lalla, A. Maymin, and S. Purchase, "The Huggable: A Therapeutic Robotic Companion for Relational, Affective Touch," presented at IEEE Consumer Communications and Networking Conference, 2006.

[16] J. Pineau, M. Montemerlo, M. Pollack, N. Roy, and S. Thrun, "Towards robotic assistants in nursing homes: Challenges and results," Robotics and Autonomous Systems, vol. 42, pp. 271-281, 2003.

[17] M. E. Pollack, L. Brown, D. Colbry, C. Orosz, B. Peintner, S. Ramakrishnan, S. Engberg, J. T. Matthews, J. Dunbar-Jacob, C. E. McCarthy, S. Thrun, M. Montemerlo, J. Pineau, and N. Roy, "Pearl: A Mobile Robotic Assistant for the Elderly," in AAAI Workshop on Automation as Eldercare, 2002.

[18] B. Graf, M. Hans, and R. D. Schraft, "Care-O-bot II-Development of a Next Generation Robotic Home Assistant," Autonomous Robots, vol. 16, pp. 193-205, 2004

[19] C. Parlitz, W. Baum, U. Reiser, and M. Hagele, "Intuitive HumanMachine-Interaction and Implementation on a Household Robot Companion," Lecture notes in computer science, vol. 4557, pp. 922, 2007.

[20] A. Cesta, G. Cortellessa, F. Pecora, and R. Rasconi, "Supporting Interaction in the Robo Care Intelligent Assistive Environment," Proceedings of AAAI Spring Symposium on Interaction Challenges for Intelligent Assistants, pp. 18-25, 2007.

[21] F. D. Davis, "Technology Acceptance Model for Empirically Testing New End-user Information Systems Theory and Results," in Unpublished Doctoral Dissertation: MIT, 1986.

[22] F. D. Davis, "Perceived usefulness, perceived ease of use, and user acceptance of information technology," MIS Quarterly, vol. September, 1989.
[23] V. Venkatesh, M. G. Morris, G. B. Davis, and F. D. Davis, "User Acceptance of Information Technology: Toward a Unified View," MIS Quarterly, vol. 27, pp. 425-478, 2003.

[24] R. Looije, F. Cnossen, and M. A. Neerincx, "Incorporating Guidelines for Health Assistance into a Socially Intelligent Robot," presented at Proceedings RO-MAN, 2006.

[25] H. Van der Heijden, "User acceptance of hedonic information systems," MIS quarterly, vol. 28, 2004.

[26] H. Sun and P. Zhang, "Causal Relationships between Perceived Enjoyment and Perceived Ease of Use: An Alternative Approach," Journal of the Association for Information Systems, vol. 7, 2006.

[27] M. Y. Yi and Y. Hwang, "Predicting the use of web-based information systems: self-efficacy, enjoyment, learning goal orientation, and the technology acceptance model.," International Journal of HumanComputer Studies vol. 59, 2003.

[28] T. Chesney, "An Acceptance Model for Useful and Fun Information Systems," Human Technology, vol. 2, 2006.

[29] B. Reeves and C. Nash, The Media Equation: How People Treat Computers, Televisions, and New Media as Real People and Places. New York: Cambridge University Press, 1996.

[30] T. Bickmore and D. Schulman, "The Comforting Presence of Relational Agents," presented at Proceedings of CHI, 2006.

[31] C. F. DiSalvo, F. Gemperle, J. Forlizzi, and S. Kiesler, "All robots are not created equal: the design and perception of humanoid robot heads," presented at Proceedings of the conference on Designing interactive systems: processes, practices, methods, and techniques, 2002.

[32] K. M. Lee and C. Nass, "Designing social presence of social actors in human computer interaction," presented at Proceedings of the SIGCHI conference on Human factors in computing systems, 2003.

[33] B. G. Witmer and M. J. Singer, "Measuring Presence in Virtual environments: A Presence Questionnaire," Presence, vol. 7, pp. 225-240, 1998.

[34] M. Lombard and T. B. Ditton, "At the heart of it all: The concept of presence," Journal of Computer-Mediated-Communication, vol. 3, 1997.

[35] K. Dautenhahn, "Roles and functions of robots in human society: implications from research in autism therapy," Robotica, Volume 21 Issue 4, vol. august, 2003.

[36] T. Fong, I. Nourbakhsh, C. Kunz, L. Fluckiger, and J. Schreiner, "The Peer-to-Peer Human-Robot Interaction Project," presented at AIAA Space, 2005.

[37] T. Fong, I. Nourbakhsh, and K. Dautenhahn, "A survey of socially interactive robots," Robotics and Autonomous Systems, vol. 42, pp. 143166, 2003.

[38] C. Breazeal, "Towards sociable robots," Robotics and Autonomous Systems, vol. 42, 2003.

[39] F. M. Gresham and S. N. Elliot, Social skills rating system: Circle Pines: American Guidance Service, 1990.

[40] K. Shinozawa, F. Naya, J. Yamato, and K. Kogure, "Differences in Effect of Robot and Screen Agent Recommendations on Human Decision-Making," IJHCS, vol. 62, pp. 267-279, 2005.

[41] T. W. Bickmore, L. Caruso, K. Clough-Gorr, and T. Heeren, "'It's just like you talk to a friend' relational agents for older adults," Interacting with Computers, vol. 17, pp. 711-735, 2005. 